\title{
Evaluation of the Perception of Oral Maxillofacial Surgery among Other Dental Specialties in King Abdulaziz University, Saudi Arabia
}

\author{
Mazen A Almasri
}

\begin{abstract}
Aim and objective: To find out if junior dental students perceive OMFS as a subject of importance in the dental school as well as the stand of other dental specialties.

Materials and methods: 531 students of 2nd, 3rd, 4th years, were selected from King Abdulaziz University (KAAU), college of dentistry, for data collection. The senior years of 5th, 6 th, and internship were excluded. A survey was conducted, which consisted of questions related to participants' demographic characteristics and their career priorities. Participants' responses were analyzed using the Chi-square test and was validated with Cronbach's alpha and binary regression analysis.

Results: The findings showed that most of the students perceived general dentistry as the most important subject of study (76\%), while, Orthodontics and OMFS came second (60\%). On the contrary; forensic dentistry and oral radiology were found to be significantly under-estimated ( $20 \%$ and $26 \%$, respectively), as the majority of the students found those subjects not to be of any importance. Cronbach's Alpha test proved that the obtained results were reliable results between the variables.

Conclusion: Dental students perceived OMFS as an important topic among other dental specialties, while perceived forensic dentistry and oral radiology as of not important. However, it is clear that junior dental students considered general dentistry to be the main area of focus and interest. Such might indicate that precollege orientation program is needed to clarify the importance of different specialties as well as the future career line afterword.

Clinical significance: The comprehension of different dentistry lines is needed among dental students. Such can be accomplished via pre and intra-college orientation programs.

Keywords: Dentistry, Knowledge, Oral Maxillofacial Surgery, Specialty perception.

World Journal of Dentistry (2022): 10.5005/jp-journals-10015-1900
\end{abstract}

\section{INTRODUCTION}

It is identified that motivated and skilled individuals are effective in providing dental health service to the society. Research on student's motivation and anticipations of dental practitioners can assist the health authorities to develop a model to recruit and retain experts that benefit the community. ${ }^{1}$ Understanding the factors affecting the selection of a dental profession are essential to orient dental students and residency training programs anticipations. $^{2}$

Several studies have indicated that the majority of the dental students' desire to continue their education toward specialization in the field of interest. This has considerable implications for the dental workforce planning in any country. ${ }^{3}$ A striking balance between demand and supply is unavoidable with an elevation in demand for the specialized dental treatment and with an elevation in supply of dental institutions. ${ }^{4}$ However, the perception of the dental specialties among junior dental students is considered vague, due to the lack of a clear precollege orientation programs. ${ }^{2,3}$ OMFS is considered a major specialty that conjoins dental and medical sciences together as it deals with head and neck injuries, pathology, and reconstruction. When compared to other dental specialties it takes the longest residency training programs. Hence, dental students might find it to be a complex subject to perceive.

Some factors have been reported in the literature that aided the comprehension of OMFS and other dental specialties to be chosen as
Oral Maxillofacial Surgery Department, King Abdulaziz University, Saudi Arabia

Corresponding Author: Mazen A Almasri, Oral Maxillofacial Surgery Department, King Abdulaziz University, Saudi Arabia, Phone: +966561041004, e-mail: malmasri@kau.edu.sa; Mazen_ajm@yahoo.com How to cite this article: Almasri MA. Evaluation of the Perception of Oral Maxillofacial Surgery among Other Dental Specialties in King Abdulaziz University, Saudi Arabia. World J Dent 2022;13(2):144-147.

Source of support: Nil

Conflict of interest: None

a line of study and career such as; helping people, the artistic nature of the career, the ability to be self-employed, and the perception of higher social status and income. ${ }^{5,6}$ However, a truthful perception of all the dental specialties is needed, and such would be if applied via boot-camp career programs at high school and precollege years to orient students to different working lines in the community. 5,6

There are merely restricted number of studies carried out on dental specialty and career preferences in Saudi Arabia., ${ }^{7,8}$ Much remains to be explored regarding the perceptions of dental students and factors affecting their selection. The current literature is scarce on students' perceptions of OMFS and how is that affecting the college years and future career choice. Thus, the objective of this study is to assess student's perception of OMFS and dental

(c) The Author(s). 2022 Open Access This article is distributed under the terms of the Creative Commons Attribution 4.0 International License (https://creativecommons. org/licenses/by-nc/4.0/), which permits unrestricted use, distribution, and non-commercial reproduction in any medium, provided you give appropriate credit to the original author(s) and the source, provide a link to the Creative Commons license, and indicate if changes were made. The Creative Commons Public Domain Dedication waiver (http://creativecommons.org/publicdomain/zero/1.0/) applies to the data made available in this article, unless otherwise stated. 
specialties; to determine which of them is perceived important and which is not, from their point of view.

\section{Materials and Methods}

The present cross-sectional study was reviewed and approved by the ethics committee of the College of Dentistry Research Center, King Abdulaziz University (KAAU), Jeddah, Saudi Arabia. Informed consent was obtained from each participant according to the ethical principles of the Institutional Review Board (IRB). The sample size of 500 students was assessed by G-Power software, version 3.1.9.4. based on an alpha of 0.05 , power of $85 \%$, assuming effect size 0.5 needed to detect difference among the students.

This study has targeted second, third, and fourth-year dental students studying at KAAU, (5th, 6th, and internship years were excluded). The total of 600 questionnaires (closed ended questions) were distributed manually in the lecture rooms. The objective of the survey was explained to the participants and was written on the preface of the questionnaire.

The items of the questionnaire were developed after an explicit review of previously published literature. A pilot study of the questionnaire was conducted in English language with 30 randomly selected students to determine any barriers and essential changes were then made accordingly. The random selection was performed by numerous systems in which every student had an equally possible chance of participation. These students were excluded from the final analysis. The questionnaire was divided into demographic, perception of importance, and final $\mathrm{GPA}$, in the form of closed answers.

The students had indicated their preference among the available specialties and general dentistry as one of them. ${ }^{2,10}$ All the items were rated on a 4-point Likert rating scale; extremely important field (1), important field (2), neutral (3), and less important field (4).

The Statistical Package for Social Sciences (SPSS, version 20, IL, USA) was used to analyze the data collected for completeness and fulfillment of the objectives. Cross-tabulations with chi-square tests were used to complete statistical analysis. A p-value of less than 0.05 was set as the level of significance. The internal consistency of the two categories of factors influencing specialty or general dentistry preferences and career options was evaluated through Cronbach's alpha. The number and percentages of the responses were determined through descriptive statistics. Binary logistic regression was used for determining the factors associated with each specialty.

\section{Results}

A 531 student-response was received (response rate 88.5\%), and the data was collected and tabulated for analysis. It presented $59.8 \%$ male and $40.2 \%$ female students. Among all these students, $76.6 \%$ had Saudi nationality and the remaining $23.4 \%$ were non-Saudi nationals. The majority of the students were Saudi because the study was conducted in one national institute. It was shown that $84.9 \%$ were either single or divorced, while the remaining $14.8 \%$ were married. The age of these students ranged from 20 to 26 years, in which $76 \%$ aged $22-24$ years. The students were asked about the final expected GPA and found that $72.1 \%$ of the student were very hopeful as they were expecting GPA of 3-4 out of 4. However, $27.8 \%$ of the students were not satisfied with their performance and were expecting a GPA score of 2-3 out of 4 (Table 1). It was found that the gender has a correlation with the outcome unlike the other parameters.

After obtaining the demographic details of the students, they requested for their specialty perception, and career interest. It was clear that general dentistry recorded the highest importance rate among all the 531 responders (76\%). OMFS scored an importance perception in about $60 \%$, and oral pathology and medicine scored $80 \%$. The specialty of prosthodontics scored $50 \%$ chance between being at the important zone vs the neutral/less important zone. It is very interesting that, at the neutral/not important zone; forensic dentistry and oral radiology scored $80 \%$ and $74 \%$, respectively. Which proves the lack of knowledge in regard to the importance of those two topics. The results were validated

Table 1: Participant's demographics

\begin{tabular}{|c|c|c|c|}
\hline Variable & Frequency $(n=531)$ & Percentage (\%) & $p$ values \\
\hline Gender & & & 0.184 \\
\hline Male & 317 & $59.8 \%$ & \\
\hline Female & 214 & $40.2 \%$ & \\
\hline Nationality & & & $0.000^{*}$ \\
\hline Saudi & 407 & $76.6 \%$ & \\
\hline Non-Saudi & 124 & $23.4 \%$ & \\
\hline Marital Status & & & $0.000^{*}$ \\
\hline Single/Divorced & 452 & $84.9 \%$ & \\
\hline Married & 79 & $14.8 \%$ & \\
\hline Age & & & $0.000^{*}$ \\
\hline $20-22$ years & 56 & $10.5 \%$ & \\
\hline $22-24$ years & 403 & $76 \%$ & \\
\hline $24-26$ years & 72 & $13.5 \%$ & \\
\hline Expected CGPA & & & $0.000^{*}$ \\
\hline Between 2-3 & 148 & $27.8 \%$ & \\
\hline Between 3-4 & 383 & $72.1 \%$ & \\
\hline
\end{tabular}

$*(p<0.05)$ 
using the Cronbach's Alpha reliability test and recorded the value of seven, and such considered as reliable. Further validation was done with binary regression and such obtained a nonsignificant outcome $(p<0.05)$ (Table 2).

The observation among specialties and the questions related to the importance of the field was measured using a Spearman's correlation to analyze the interrelation between the two parameters, 0.254 (Table 3).

\section{Discussion}

Students in every faculty are concerned about their careers and their future options. They seek some mentoring before completing their graduate degree. The aim of the present study is to evaluate student's perception of the dental specialties and to perceive an idea of importance level of each subject.

The analysis of the responses disclosed a very diversified answer. Most of the students wanted to pursue their career with advanced general dentistry because it has a wide scope. Studies from other universities and regions also validate our findings that general dentistry and advanced general dentistry are the most selected field among the students. ${ }^{2,9}$ The influence of gender, age, and marital status on the selection of these specialties was tested and did not find any significant results in general dentistry. However, oral radiology and periodontics selection carry gender discrimination as most of the female students considered oral radiology as a less important field, however, male students considered it important.
Similar results were found in case of restorative and esthetic dentistry, where female students showed higher interest when compared to male students. Baker et al. reported that females considered esthetics as the most important field in comparison to any other specialty in dentistry, among his group. ${ }^{12}$

OMFS is considered a major specialty that deals with head and neck injuries, pathology, and reconstruction. It usually takes the longest training years when compared to other dental specialties. Also, it was measured as an important specialty by the male and female students equally. Another study reported that males were leaning to the importance of OMFS more than females, a study conducted by Halawany et al. ${ }^{2}$ Such results indicate the variation in study sample according to the pre-emptive perception mainly. ${ }^{11}$ The field of forensic dentistry was found to be significantly underestimated..$^{10,13}$ Most did not give any importance to this field, as per our survey, which could be due to the lack of knowledge. ${ }^{14-16}$

Table 2 shows no significant differences in all the parameters in relation to the type of question or the specialty chosen by students. This was unparallel with the results published by Alwadani et al. ${ }^{10}$ and Halawany et al. ${ }^{2}$ The aforementioned, presented the relation between different specialties and the choice of" "Extremely Important Field", and the result showed high response in the following topics: general dentistry, oral medicine and pathology, restorative and esthetic dentistry, as they scored $76.4 \%, 66.4 \%$, and $59.6 \%$, respectively. Alwadani et al. performed a similar study in a different city and found different results. Interestingly, endodontics recorded the

Table 2: Students interest toward different specialties

\begin{tabular}{|c|c|c|c|c|c|c|c|c|c|}
\hline \multirow[b]{2}{*}{ Specialties } & \multicolumn{2}{|c|}{ Extremely important field } & \multicolumn{2}{|c|}{ Important field } & \multicolumn{2}{|c|}{ Neutral } & \multicolumn{2}{|c|}{ Less important field } & \multirow[b]{2}{*}{ Total N (\%) } \\
\hline & $\begin{array}{c}\text { Frequency } \\
(n=531)\end{array}$ & Percentage & $\begin{array}{c}\text { Frequency } \\
(n=531)\end{array}$ & Percentage & $\begin{array}{c}\text { Frequency } \\
(n=531)\end{array}$ & Percentage & $\begin{array}{c}\text { Frequency } \\
(n=531)\end{array}$ & Percentage & \\
\hline $\begin{array}{l}\text { Restorative } \\
\text { and esthetic }\end{array}$ & 317 & 59.6 & 89 & 16.7 & 87 & 16.3 & 38 & 7.15 & $531(100)$ \\
\hline Prosthodontics & 115 & 21.6 & 175 & 32.9 & 118 & 22.2 & 123 & 23.1 & \\
\hline Orthodontics & 47 & 13.3 & 252 & 47.4 & 63 & 9.98 & 169 & 31.8 & \\
\hline $\begin{array}{l}\text { Oral and } \\
\text { maxillofacial } \\
\text { surgery }\end{array}$ & 116 & 21.8 & 208 & 39.1 & 93 & 17.5 & 114 & 21.4 & \\
\hline $\begin{array}{l}\text { General } \\
\text { dentistry }\end{array}$ & 408 & 76.8 & 75 & 14.1 & 40 & 7.53 & 08 & 1.5 & \\
\hline Periodontics & 237 & 44.6 & 165 & 31.0 & 114 & 21.4 & 15 & 2.82 & \\
\hline $\begin{array}{l}\text { Forensic } \\
\text { dentistry }\end{array}$ & 79 & 14.8 & 27 & 5.08 & 208 & 39.1 & 217 & 40.86 & \\
\hline $\begin{array}{l}\text { Oral medicine } \\
\text { and oral } \\
\text { pathology }\end{array}$ & 358 & 67.4 & 73 & 13.7 & 76 & 14.3 & 24 & 4.5 & \\
\hline Oral radiology & 54 & $10.1 \%$ & 82 & $15.4 \%$ & 112 & $21.09 \%$ & 283 & $53.2 \%$ & \\
\hline $\begin{array}{l}\text { Advanced oral } \\
\text { dentistry }\end{array}$ & 54 & $10.1 \%$ & 254 & $47.8 \%$ & 196 & $36.9 \%$ & 27 & $5.08 \%$ & \\
\hline$p$ values & & 60 & & & & 35 & & & \\
\hline
\end{tabular}

Table 3: Spearman's correlations between specialties and the questions related to the importance of field in the studied sample

\begin{tabular}{|c|c|c|c|c|}
\hline Variables & & & Different specialties & $\begin{array}{l}\text { Questions related to the } \\
\text { importance of field }\end{array}$ \\
\hline \multirow[t]{2}{*}{ Spearman's rho } & Different specialties & Correlation coefficient & - & $0.254^{*}$ \\
\hline & & Sig. (2-tailed) & & 0.000 \\
\hline
\end{tabular}

${ }^{*}$ Correlation is significant at the 0.01 level (two-tailed) 
highest percentage (22.4\%) among the other dental specialties. Such goes along with our study as endodontics was considered as part of general dentistry in our work. ${ }^{10}$ In contrast to Alwadani et al. ${ }^{10}$ who found prosthodontics and orthodontics of much less interest rate, recording $12.7 \%$ and $13.9 \%$, respectively, while in our results recorded prosthodontics recorded $53 \%$ importance, while orthodontics recorded $60 \%$ of importance. ${ }^{10}$ This might be explained by the different social background, education, and living environment between the two cities Jeddah and Jazan. Such conforms the variation in recording the oral medicine/pathology which showed 7\% only in Jazan University while around $74 \%$ in Jeddah.

The study has some limitations such as the questionnaire-based type of study at a single institute and the lack of comparison group which could have been compared with more senior students at the college to gauge if any variation in the perception does exist. A multicenter study to compare the perception at different universities will help analyzing the geographic variation effect on the outcomes.

\section{Conclusion}

The perception of OMFS among junior dental students was of importance, while completely the opposite when looking at Forensic dentistry and oral radiology which may be considered importance once understood in details. ${ }^{16,17}$ Junior students are eager about general/esthetic dentistry and considered them the most important.

\section{References}

1. Haghani J, Torabi M, Nazari M. Postgraduate specialties interest and related factors in dental students at Kerman University of Medical Sciences (Iran-2016). EC Dent Sci 2018:1879-1886. DOI: 10.30476/DENTJODS.2020.82596.1024

2. Halawany HS, Binassfour AS, AlHassan WK, et al. Dental specialty, career preferences and their influencing factors among final year dental students in Saudi Arabia. Saudi Dent J 2017;29(1):15-23. DOI: 10.1016/j.sdentj.2016.12.001

3. Kanmodi KK, Badru Al, Akinloye AG, et al. Specialty choice among dental students in Ibadan, Nigeria. Afr J Health Prof Educ 2017;9(1):21-23. DOI: 10.7196/AJHPE.2017.v9i1.670

4. Giummarra A, Inderjeeth K, Celebic D, et al. Factors influencing consideration of dental specialisation: a survey of current dental students at the University of Western Australia. Ann Stomatol 2018;9(1):27-34. DOI: 25838007
5. Sonkar J, Bense S, ElSalhy M. Factors affecting pre-doctoral dental students' selection of advanced dental education: a cross-sectional study. J Dent Educ 2020;1-11. DOI: 10.1002/jdd.12343

6. Shrestha M, Shrestha M, Dhami B. Attitude of bachelor of dental surgery students towards specialization in Kantipur Dental College, Kathmandu. J Kantipur Dent Coll 2020;1(1):16-19.

7. Alnomay NS, Aldebassi B, Alghomlas AD, et al. Choice of dental specialties among dental students and associated influencing and motivating factors in Saudi Arabia. J Health Inform Dev Ctries 2018;12(2):1-20.

8. Al Subait A, Ali A, Andijani MI, et al. Factors influencing the career choices among medical university students of King Saud Bin Abdulaziz University, Riyadh Saudi Arabia; a cross-sectional study design. Saudi J Dent Res 2017;8:73-78. DOI: 10.1016/j.sjdr.2016.05.003

9. Al-Nomay NS, Alghomlas BD, Abdulsalam S. Influence of the knowledge and practices on dental students career choices of specialty in Saudi Arabia. Edelweiss Publication, 2020. DOI: 10.33805/2572-6978.138

10. Alwadani M, Mashyakhy MH, Jali A, et al. Dentists and dental intern's preferences of root canal treatment with restoration versus extraction then implant-supported crown treatment plan. Open Dent J, 2019;13:93-100. DOI: 10.2174/1874210601913010093

11. Field JC, Cowpe JG, Walmsley AD. The graduating European dentist: a new undergraduate curriculum framework. Eur J Dent Educ 2017;21:2-10. DOI: 10.1111/eje.12307

12. Baker RS, Fields Jr. HW, Beck FM, et al. Objective assessment of the contribution of dental esthetics and facial attractiveness in men via eye tracking. Am J Orthod Dentofacial Orthop 2018;153(4):523-533. DOI: 10.1016/j.ajodo.2017.08.016

13. Mânica S, Gorza L. Forensic odontology in the 21st centuryidentifying the opinions of those behind the teaching. J Forensic Leg Med 2019;64:7-13. DOI: 10.1016/j.jflm.2019.03.006

14. Gambhir RS, Singh G, Talwar PS, et al. Knowledge and awareness of forensic odontology among dentists in India: a systematic review. J Forensic Dent Sci 2016;8(1):2-6. DOI: 10.4103/0975-1475.176954

15. Behura SS, Mukherjee S, Nishat R, et al. Assessment of the awareness of knowledge of dental records in forensic dentistry among undergraduate dental students. Indian J Med Forensic Med Toxicol 2020;14(1):123-129. DOI: 10.37506/ijfmt.v14i1.26

16. Abdul NS, Alhazani L, Alruwail R, et al. Awareness of forensic odontology among undergraduate, graduate, and postgraduate dental students in Riyadh, Saudi Arabia: a knowledge-, attitude-, and practice-based study. J Forensic Dent Sci 2019;11(1):35. DOI: 10.4103/jfo.jfds_52_19

17. Renuka K, Leela B, Rajesh N, et al. Knowledge, awareness and practices of forensic dentistry: a questionnaire study among dental personnel practicing in Bhimavaram Town, South India. Indian J Public Health Res Dev 2019;10(12):1829-1833. DOI: 10.37506/v10/i12/2019/ijphrd/192132 